\title{
AS NOVAS FIGURAS CONTRATUAIS E A AUTONOMIA DA VONTADE
}

\author{
Fernando Campos Scaff \\ Advogado em São Paulo
}

\begin{abstract}
Resumo:
As relações jurídicas emergentes da sociedade contemporânea ensejaram restrições impostas a completa autonomia da vontade, que culminaram com a objetivação dos contratos.

Neste contexto, ao lado do modelo clássico de contrato emergem novas formas contratuais, como os contratos tipos e os contratos de adesão, que prescindem da conceituação clássica da autonomia da vontade, mas que pelo sinalagma que apresentam e pela sua estrutura negocial traduzem uma nova perspectiva dessa mesma autonomia.
\end{abstract}

\begin{abstract}
:
The jural relations coming from the modern society gave place to restrictions imposed to a complete will autonomy, that ends with the contracts objectivity.

In this context, besides the classics models contracts, new kinds of contracts appear, for instance the standart and adhesion contracts, that are excluded from the classic concept of will autonomy. Although this exclusion, these new contracts are seen as synallagmatic ones. In addition to this, their negocial structure reflect a new vision of that so-called autonomy.
\end{abstract}

Unitermos: Autonomia da vontade - nova perspectiva.

Sumário:

Introdução

I A evolução das concepções

II - A objetivação dos contratos

III - O contrato e sua função social

IV O contrato e o "contato social"

V A intervenção estatal e as restrições da autonomia individual

VI - Conclusão os novos papéis do contrato

Bibliografia 


\section{Introdução}

Dentre as questões que ainda se colocam sob a perspectiva da teoria do negócio jurídico e dentre as categorias das fontes das obrigações, verifica-se que não se superaram as dúvidas e investigações relativas à própria idéia da importância do contrato, no âmbito das relações jurídicas, bem como de sua interpretação, no interior desta categoria.

Questiona-se, de um lado, a importância da vontade na composição dos tipos contratuais, seu condicionamento e sua limitação frente às categorias contratuais que integram, intensamente, a vida contemporânea, e que prescindem da visualização efetiva da clássica convergência de vontades, no sentido de condição necessária para a própria formação do contrato.

Por outro lado, pergunta-se até que ponto esta convergência de vontades deixou, efetivamente, de integrar a figura do contrato e se não é verdadeiro que tal instituto, variando de acordo com as necessidades de rapidez e homogeneização, próprias do atual estágio de desenvolvimento econômico, incitam os doutrinadores a, com base na revisão dos conceitos firmados, relativos a esta noção de contrato, buscar adaptações da idéia clássica, mantendo o instituto e adequando-o a tais necessidades do tráfego.

Talvez esta seja a melhor alternativa, e sobre ela possam se debruçar os estudiosos, no sentido de buscar adaptações no modo de conceber o instituto, as quais, sem dúvida, se fazem necessárias, bem como identificar, na categoria mesma dos contratos ou naquela de institutos diversos, outras figuras que surgem a todo o tempo, na rede de relações jurídicas que se formam, decorrentes do amplo contato social, e que devem merecer, igualmente, classificação no sistema.

Uma breve visão destas situações constitui, pois, o objeto do presente estudo.

I A evolução das concepções

A idéia clássica do contrato, baseada na liberdade individual dos contratantes, reflete, mais do que tudo, a concepção deste conceito como sendo um elemento fundamental de expressão do momento pelo qual então passava a civilização européia, buscando superar as estruturas vinculadas às monarquias absolutistas e assim criando instrumentos próprios à efetivação do poder da 
ascendente burguesia, que buscava e impunha sua afirmação. Tal se procurou fazer através do desenvolvimento de institutos que, de alguma forma, pudessem privilegiar a idéia da ampla autonomia da vontade e de uma formulação que tivesse como pressuposto a rígida igualdade das partes que negociavam.

Neste contexto, como bem colocou Gilmore, analisando as imagens trazidas por Friedman, vislumbra-se que o modelo da teoria clássica do contrato era muito similar ao modelo daquela que define a teoria econômica liberal o credo do laissez-faire, considerando-se que, em ambos os modelos, "as partes poderiam ser tratadas como unidade econômica individual, em teoria, capazes de gozar de uma completa liberdade de ação e decisão." A teoria econômica do laissez-faire se reduziria, pois, a qualquer coisa deste tipo: que se todos nós fizéssemos exatamente aquilo que mais nos agrada, tudo se resolveria certamente pelo melhor. ${ }^{1}$

É a idéia da prevalência da vontade, tão mitigada na relação desproporcional existente entre o súdito e o soberano, e que, segundo as idéias libertárias que pretendiam garantir à burguesia a resposta à sua ascensão econômica, tornava-se valorizada, como verdadeira expressão da liberdade humana.

É o que foi exposto, igualmente, por Véronique Ranouil, notando que "a doutrina clássica fazia da vontade o elemento essencial do contrato $e$ o fundamento de sua força obrigatória. Também considerava-se que o contrato é justo, pois que qualquer homem razoável e livre não pode consentir a se comprometer para se prejudicar" 2

Não tardou para que se verificasse que tal pretensa igualdade entre os contratantes constituía-se numa interpretação muito mais formal do que material, considerando-se as distinções fáticas que atribuem vantagens ou melhores condições negociais a uma das partes, o que possibilita a imposição da vontade de um àquela do outro contratante, diminuindo ou, por vezes, simplesmente anulando a pretensa intenção deste em estabelecer os termos do contrato firmado ou até de optar pela não contratação. ${ }^{3}$

1. Grant Gilmore, La Morte del Contrato, tradução de Andrea Fusaro, $1^{\mathrm{a}}$ ed., Milão, Giuffrè,.1988, p. 85.

2. Véronique Ranouil, L'Autonomie de la Volonté, $1^{\mathrm{a}}$ ed., Paris, Presses Universitaires de France, 1980, p. 133.

3. Como se verifica, por exemplo, nos contratos de adesão, com o controle monopolístico de uma das partes sobre determinado serviço ou produto, colocado no mercado. 
Entende-se, pois, que " $a$ justiça não provém naturalmente do contrato, uma vez que os contratantes não são livres ou iguais: a sua igualdade nominal dissimula sua desigualdade real. Chega-se que as conclusões não são livremente consentidas, mas impostas pela parte mais forte àquela mais fraca" ${ }^{4}$

Impôs-se, de tal modo, novamente a necessidade de intervenção do Estado, para garantir que um efetivo equilíbrio contratual pudesse ser propriamente alcançado, beneficiando-se aqueles que não se aproveitam, no ato negocial, desta igualdade classicamente imaginada, e meramente formal.

Neste contexto justificou-se tal nova intervenção, considerado o fato, por exemplo, que a "preocupação quanto à moralização do contrato se manifesta no domínio dos contratos de adesão e mais geralmente naquele da interpretação dos atos jurídicos, assim como que a propósito da questão espinhosa do justo preço, do justo salário e do problema relativamente novo da redução das obrigações excessivas" 5

Além disso, alcançou-se a conclusão de que não só não são iguais as partes que contratam, colocando-se em planos distintos de possibilidades econômicas, dispondo de graus diversos de informações quanto àquilo sobre o que negociam, bem como se verificou que podem igualmente se alterar, no curso da própria contratação, as expectativas e as posições contratuais inicialmente previstas, pelo que o contrato não pode representar, como a princípio se pretendia, norma insuperável sob a qual, de toda maneiro, deveriam se submeter as partes, impossibilitada toda e qualquer modificação.

Tais circunstâncias representaram forte razão para o repensamento da idéia da autonomia da vontade e de toda concepção clássica de contrato, considerando-se, sobretudo, que a vontade não tem este dom de referência absoluta $\mathrm{e}$ intensamente presente em todas as relações jurídicas existentes, mas que se altera em importância, dependendo de como se comportem as próprias circunstâncias, presentes e futuras, envolvidas na contratação. Assim, pois, que valem as lições de Menezes Cordeiro, reconhecendo que as condições da doutrina clássica para "regular a alteração tais circunstâncias esgotou, com Larenz, as suas potencialidades. A sua ligação perene à teoria da vontade, clara em Windscheid, perceptivel e assumida em Oertmann e presente, embora de modo tênue, nos

4. Véronique Ranouil, ob. cit., p. 133.

5. Véronique Ranouil, ob. cit., p. 133. 
críticos da base negocial oertmanniana e em Larenz, dificultava a integração dogmática e paralisava a sua aplicação prática. A dimensão do jurídico, ainda quando querida, é qualitativamente diferente de qualquer vontade humana individual; a vontade das partes, naturalisticamente entendida, não pode facultar soluções que pressuporiam a presença de elementos estranhos, por definição, no momento necessário, ao conhecimento das pessoas implicadas" 6

Ora, evoluindo a sociedade de tal maneira, alterando-se a necessidade e o ritmo das contratações, configurando-se, ademais, circunstâncias que prescindem da declaração da vontade das partes, esta tal como reconhecida pela doutrina clássica, a alteração envolvendo as perspectivas de conceituação e interpretação dos contratos, verificada no âmbito doutrinário, passou a ser consequeência absolutamente natural e previsível.

Sendo assim, e acompanhando o relato de Roppo, duas perspectivas se formaram: 1. acreditar que não houve, na realidade, tantas mudanças, acreditando que os contratos e o direito dos contratos são os mesmos que existiam no século dezenove; 2. acreditar que a vontade dos contratantes não conta, acreditando que, por tal fato, há de se entender que houve um declínio e mesmo uma "morte" dos contratos atuais. $^{\text {? }}$

A verdade, contudo, parece não se encontrar com qualquer destas interpretações. De um lado, a idéia de contrato, como inocente fruto da convergência de vontades livres e iguais, que se unem na perspectiva de uma finalidade que sirva a ambas, não se traduz em grande parte das contratações existentes no momento atual. Por vezes, reduze-se mesmo esta vontade à mera determinação de contratar ou de não-contratar, e ainda, em muitas ocasiões, nem a isso, impondo-se peremptoriamente a contratação aos indivíduos, considerado o monopólio de fato existente, atribuído a uma das partes, e a absoluta necessidade daquele bem ou serviço "oferecido"

Por outro lado, não há por isso que se entender, em virtude desta relativização da vontade, que a mesma deixe de existir nos contratos formados, ou mesmo que tal instituto deixe de representar fenômeno presente e que se realiza

6. Antonio Manuel da Rocha e Menezes Cordeiro, Da Boa-Fé no Direito Civil, v. 2, $1^{2}$ ed., Coimbra, Almedina, 1984, p. 1.051.

7. Enzo Roppo, O Contrato, $1^{2}$ ed., Coimbra, Almedina, 1988, pp. 297 e 298. 
mesmo numa dimensão tal que multiplica ao infinito aquelas ocorrências havidas na época de formação clássica do instituto.

De fato, o contrato existe e, numa determinada perspectiva, está mais forte e pujante do que nunca. O que ocorre, na verdade, é a necessidade de compreensão de alguns dos fenômenos que acompanharam tal instituto, e que, de forma geral, objetivaram-no, como imposição da moderna economia de massas.

Inegável, pois, é a tendência, bem percebida por Roppo, "para uma progressiva redução do papel e da importância da vontade dos contraentes, entendida como momento psicológico da iniciativa contratual: esta tendência, que podemos definir como "objetivação do contrato" leva a redimensionar, sensivelmente, a influência que o elemento voluntarista exerce, quer em relação à definição geral do próprio conceito de contrato, quer em relação ao tratamento jurídico concreto de cada relação" 8

\section{A objetivação dos contratos}

Assim, considerava-se o contrato como expressão pura e direta da livre expressão da vontade de homens iguais e livres, que passaram a uma situação de igualdade formal, decorrência da queda do "Antigo Regime" Segundo Roppo, neste mesmo sentido, é necessário que se veja a "vontade humana como a fonte primária de todo o efeito jurídico, a energia criadora dos direitos e das obrigações legais." Dela defluiu, pois, a assim denominada "Teoria da Vontade" como chave para entender, inicialmente, a disciplina das trocas contratuais, considerando-se que as conseqüências do contrato deveriam estar em perfeito acordo com as representações mentais das partes, e que o direito deveria reagir a qualquer imperfeição ou perturbação do processo de formação da vontade dos contraentes, cancelando a operação em que - por ausência ou defeito de seu pressuposto psíquico - faltasse este que é considerado o seu próprio fundamento. ${ }^{10}$

\footnotetext{
8. Ob. cit., p. 297.
}

9. Ob. cit., p. 297.

10. Conf. Roppo, ob. cit., pp. 297 e 298. Assim, igualmente, foi acolhido por nosso Código Civil, de acordo com a disposição expressa pelo seu art. 85: "Nas declarações de vontade, se atenderá mais à sua intenção que ao sentido literal da linguagem". 
Efetiva expressão da liberdade individual dos homens, representa a autonomia privada, no dizer de Aguila-Real, verdadeiro "reconhecimento aos indivíduos de um poder para regular suas relações como lhes pareça conveniente se justifica porque é expressão do direito a autodeterminação da pessoa humana." "1

Conhecido o anterior período intervencionista, a elevação da idéia da autonomia da vontade como um princípio quase sagrado, imposto no período de formulação da teoria clássica do contrato, significou uma reação às restrições anteriores, explicável também, portanto, nesta perspectiva histórica. De fato, " $a$ autonomia privada se concebe como um espaço livre da ingerência estatal deixado ao jogo das forças dos indivíduos frente ao intervencionismo estatal que caracterizou o Antigo Regime."12

Especificamente, segundo delimita Orlando Gomes, “o princípio da autonomia da vontade particulariza-se no direito contratual na liberdade de contratar. Significa o poder dos indivíduos de suscitar, mediante declaração de vontade, efeitos reconhecidos e tutelados pela ordem jurídica." 13

Segundo a concepção clássica, tal conceito de liberdade contratual “abrange os poderes de auto-regência dos interesses, de livre discussão das condições contratuais e, por fim, de escolha do tipo de contrato conveniente à atuação da vontade. Manifesta-se, por conseguinte, sob tríplice aspecto: a) liberdade de contratar propriamente dita; b) liberdade de estipular o contrato; $c$ ) liberdade de determinar o conteúdo do contrato. "14

Os problemas, contudo, com uma visão estrita de tais princípios, logo se fizeram presentes. De fato, a vontade pode ser maldeclarada, deixando de expor aquilo que efetivamente se pretendia ou atuando contra as legítimas expectativas do destinatário da mesma. Por outro, o destinatário poderia receber de forma inadequada tal manifestação, pelo que a imposição de regras de comportamento, que dissessem respeito ao que seria a interpretação correta, tornaram-se imposições colocadas à doutrina e aos legisladores.

11. Jesus Alfaro Aguila-Real, Las Condiciones Generales de La Contratation, 1ed., Madrid, Civitas, p. 53.

12. Aguila-Real, ob. cit., p. 59.

13. Orlando Gomes, Contratos, $12^{\mathrm{a}}$ ed., Rio de Janeiro, Forense, 1990, p. 25.

14. Cf. Orlando Gomes, ob. cit., pp. 26 e 27. 
Neste sentido, Maria Costanza nos elucida que "geralmente, a tese, segundo a qual objeto da operação hermenêutica é a vontade dos contratantes, é considerada pouco atendivel e por vezes superada, considerada a fisionomia que o contrato assumiu na legislação atual. Os estudos desenvolvidos já no início do século na Alemanha e posteriormente retomados e continuados na Itália, levaram a considerar o negócio jurídico e sobretudo o contrato, seja a nível teórico ou sob o plano do direito positivo, como manifestação da vontade mais do que ato de vontade." Por outro lado, "esta prevalência da declaração ou, mais genericamente, da manifestação da vontade interna influencia também a individualização do objeto da interpretação. O fato que no contrato, ou, mais em geral, no negócio jurídico assuma relevância, aos fins da determinação de suas conseqüências jurídicas, somente a vontade declarada e não também aquela que se mantém inexpressa não impede, porém, que a interpretação se realize também com indagações extracontratuais." 15

De toda a forma, é necessário que se reafirme que tal liberdade de contratar, desde o primeiro momento de sua concepção, acomodou-se entre determinados limites, estabelecidos, fundamentalmente, pelos critérios vinculados à ordem pública. De fato, em concordância com as palavras de Bessone, "sendo justo o contrato, segue-se que aos contratantes deve ser reconhecida ampla liberdade de contratar, só limitada por considerações de ordem pública e pelos bons costumes. Assim, enquanto forem observados estes limites, podem as partes convencionar aquilo que lhes aprouver, o que, de resto, constitui um aspecto da liberdade individual, consubstanciada no princípio de que é permitido tudo que não é proibido."16 Também para Orlando Gomes, "a liberdade de contratar, propriamente dita, jamais foi ilimitada. Duas limitações de caráter geral sempre confinaram-na: a ordem pública e os bons costumes. Entendia-se, como ainda se pensa, que as pessoas podem auto-regular seus interesses pelo modo que lhes convenha, contanto que não transponham estes limites."17

Porém, não demorou muito para que se verificasse que o anterior desequilíbrio, que se atribuía à intervenção estatal própria do Antigo Regime, não

15. Maria Costanza, Profili Dell'Interpretazione Del Contrato Secondo Buona Fede; $1^{\text {a ed., }}$ Milão, Giuffrè, 1989, pp. 9 e 10.

16. Darcy Bessone, Do Contrato - Teoria Geral, $3^{\mathrm{a}}$ ed., Rio de Janeiro, Forense, 1987, p. 31.

17. Ob. cit., p. 27. 
deixava de existir completamente, mesmo no âmbito das relações entre particulares que, numa condição de igualdade formal, contratam. As partes, com efeito, tendem mais às diferenças que às convergências. Os desequilíbrios entre as potencialidades, os meios de imposição da vontade de uma em detrimento da outra, bem como a possibilidade de formulação de condições que favoreçam a apenas uma das partes componentes de determinada relação jurídica, tudo isso leva a reflexões sobre esta função exponencial da autonomia da vontade, vinculada à idéia do ato de contratar.

Ainda segundo as lições de Aguila-Real, "para que o contrato seja um ato de autonomia bilateral, é necessário que se dêem todos os pressupostos que permitem a ambas as partes autodeterminar-se porque, de outra forma, teríamos heterodeterminação unilateral, com o que desaparece a legitimidade para o reconhecimento estatal de ditos atos, realizados pelos particulares. "18

De um lado, pois, é possível imaginar-se um contrato realizado por partes colocadas numa situação de equilíbrio, onde a perspectiva de ampla negociação e gestão dos próprios interesses, sem pressões causadas pela desconexão entre as partes, venha a ser conhecida. Esta equação própria ao modelo clássico de contrato, assim, subsiste. Porém, segundo Aguila-Real, este mesmo modelo "se 'corrompe' quando se denomina de igual forma à articulação jurídica de intercâmbios cuja realização ou cujo conteúdo não foi remetida pelo ordenamento à livre determinação dos particulares, como ocorre nos casos de intervenções estatais substitutivas ou eliminadoras do mercado."19

De fato, dada a característica específica de alguns produtos ou bens, existentes no mercado, mas colocados à disposição dos indivíduos por um pequeno grupo de empresas, um requisito fundamental, garantidor da efetiva liberdade contratual dos indivíduos reconhecida esta como expressão da autonomia da vontade - deixa de existir, para dar lugar a uma verdadeira imposição unilateral de condições e termos contratuais, o que, naturalmente, desvirtua aquela idéia antes apresentada.

Elemento garantidor da autonomia da vontade é, pois, na sociedade contemporânea, a existência de competição entre as fontes informadoras do mercado, permitindo aos indivíduos verdadeira liberdade de escolha, entre este ou aquele produto, este ou aquele serviço. Deste modo, “a existência de competição,

18. Cf. Darcy Bessone, ob. cit., p. 60.

19. Ob. cit., p. 62 . 
pois, garante que a renúncia para contratar seja uma alternativa razoavelmente disponivel, quer dizer, que se possa exigir ao que celebra o contrato que se atenha às conseqüências de tal celebração, optando entre várias alternativas. "20

$\mathrm{O}$ que se entende por liberdade contratual, portanto, sem dúvida mudou, como mudou a estrutura da sociedade moderna, o fluxo e a quantidade de negociações existentes, a racionalização dos métodos e das formas utilizadas.

Para que se identifique a autonomia da vontade, no mundo contemporâneo, não se pode pensar mais na exigência da completa e livre formulação das cláusulas contratuais, discutidas uma a uma pelas partes que negociam. Não é, portanto, uma ampla negociação o fundamental; fundamental é, na realidade, a competição entre as formas, permitindo a uma das partes, numa economia de escala e competitiva, escolher entre este ou aquele proponente, com liberdade de opção.

Deve-se descartar, conseqüentemente, segundo ensina o mesmo Aguila-Real, "que para que exista consentimento livre seja necessário que ambas as partes participem da elaboração do conteúdo do contrato, quer dizer, é falso que a existência de liberdade contratual venha determinada, por seu turno, pela existência de negociação. Em outras palavras, o que garante a livre decisão dos clientes não é a negociação, senão entre opções alternativas e transparentes. "21

Longe está, portanto, de se poder falar de uma verdadeira decadência ou mesmo eliminação da presença da autonomia da vontade, nas contratações. Ela existe, em sua forma clássica ou em seus moldes mais atualizados, consideradas, basicamente, o objeto e as partes envolvidas numa determinada contratação. Subsiste, pois é tal autonomia, segundo Ferri, "não a expressão de uma mera licitude ou faculdade, mas manifestação de poder, e precisamente do poder de criar, dentre os limites postos pela lei, pela norma jurídica."22

Direta é a correlação e, mais do que isso, a vinculação necessária entre tal autonomia e a própria gênese dos negócios jurídicos. De fato, "se a autonomia privada é poder pertencente aos particulares de criar normas jurídicas, é

20. Ob. cit., p. 64 .

21. Ob. cit., pp. 67 e 68 .

22. Gino Ferri, L'Autonomia Privata, $1^{a}$ ed., Milão, Dott. A. Giuffrè, 1959, p. 5. 
perfeitamente iluminada também a correlação entre os dois termos "autonomia privada" "negócio jurídico" o segundo como única expressão do primeiro. "23

O que se verifica, afinal, é que tal sistema da autonomia da vontade, necessariamente vinculado a uma discussão e formulação conjunta, pelas partes contratantes, de cada uma das cláusulas que compõem o contrato formado, não se coaduna com todas as necessidades da sociedade contemporânea. Poderia servir, como constata Roppo, a um sistema economicamente individualista e pouco dinâmico, mas não serve às exigências da "moderna economia de massa"

Para tal modelo econômico, onde as negociações jurídicas se fazem a partir do estabelecimento de uma homogeneização das relações, como própria imposição do fluxo do tráfego econômico existente, surgem, como imposições naturais, que o sistema possa, de um lado, garantir a celeridade das contratações, como reclamo da sociedade, mas, por outro, que tal celeridade seja feita sem que se perca de vista a garantia da segurança e estabilidade de tais relações.

Em resposta a esta necessidade, uma primeira resposta, dada pelo ordenamento, foi a passagem ocorrida da chamada "Teoria da Vontade" à "Teoria da Declaração" cujo ponto característico e fundamental é vincular o tratamento e a interpretação jurídica das relações aos elementos objetivos, exterior e socialmente reconhecíveis. É assim a tendência a fazer prevalecer aquilo que é socialmente transparente e que seja perceptível aos outros contratantes. ${ }^{24}$

Derivou-se, com base nesta formulação, do pólo constituído pela vontade subjetiva do que pretende a realização de um determinado interesse, ao pólo daquele que, com base no que foi efetivamente externado, é o destinatário de formas e expressão da linguagem, objetivamente concretizada, e que reage, exatamente, ao que pode, objetiva e razoavelmente, apreender daquela manifestação de vontade declarada.

Com base nesta radical mudança na concepção da autonomia da vontade, já como fruto da evolução do sistema econômico social, pretendeu-se, desde então, que fossem fornecidos os instrumentos que possibilitassem tal facilitação das contratações, fruto e necessidade da própria economia de massas. Assim, contra um dos preceitos da formulação clássica, entendeu-se possível que o contrato fosse validamente formado, vinculando os sujeitos que participam daquela

23. Cf. Gino Ferri, ob. cit., p. 6.

24. Cf. Enzo Roppo, ob. cit., pp. 297 e ss. 
relação jurídica, mesmo que, no momento em que se conclui, falte completamente a vontade a uma das partes, ou até exista uma sua vontade contrária.

III O contrato e sua função social

Não pararam, contudo, nas conseqüências derivadas da Teoria da Declaração, as idéias e formulações da doutrina, no sentido de acompanhar as necessidades da sociedade contemporânea.

De fato, a importância do contrato, ou melhor, do ato de qualquer de suas formas, é aquela de um fruto direto da liberdade pessoal dos indivíduos, na regência de seus próprios interesses. Trazendo as lições de Caio Mário da Silva Pereira, mostra-se claro que, "paralelamente à função econômica, aponta-se no contrato uma outra civilizadora em si, e educativa. Aproxima ele os homens e abate as diferenças. Enquanto o indivíduo admitiu a possibilidade de obter o necessário pela violência, não pôde apurar o senso ético, que somente veio a ganhar maior amplitude quando o contrato convenceu das excelências de observar normas de comportamento na consecução do desejado. Dois indivíduos que contratam, mesmo que não se estimem, respeitam-se. E enquanto as cláusulas são guardadas, vivem em harmonia satisfatória, ainda que pessoalmente não se conheçam. "25

O contrato e a liberdade contratual sempre tiveram tal função, eminentemente social, de afirmação da individualidade de cada um, expressa nas relações que se formam a partir de tal manifestação da vontade. Assim também se coloca a função social do contrato, "na afirmação de maior individualidade humana. Aquele que contrata projeta na avença algo de sua personalidade. $O$ contratante tem a consciência do seu direito e do direito como concepção abstrata. Por isso, realiza dentro das suas relações privadas um pouco da ordem jurídica total. Como fonte criadora do direito, o contrato assemelha-se à lei, embora de âmbito mais restrito. Os que contratam assumem, por momento, toda a força jurígena social. Percebendo o poder obrigante do contrato, o contraente sente em si o impulso gerador da norma de comportamento social, e efetiva esse impulso." 26

25. Caio Mário da Silva Pereira, Instituições de Direito Civil, v. III, $9^{\mathrm{a}}$ ed., Rio de Janeiro, Forense, 1992, p. 9.

26. Caio Mário da Silva Pereira, ob. cit., p. 10. 
Este é, portanto, o fim verdadeiro e claro desta idéia de função social do contrato, como expressão da própria liberdade dos indivíduos, em reger, livremente, seus interesses. Exaure-se, como afirma Gino Gorla, a função social do contrato, "em manter a ordem e a paz social, obedecendo ao mesmo tempo as particulares exigências de certeza e de justiça entre os particulares." 27

Reconhecer tal função social do contrato, significa, em suma, reconhecer o aludido vínculo da liberdade individual com a possibilidade de realização de negócios jurídicos.

Contudo, não se cria com tal reconhecimento, como pretenderam alguns, fundamento para a criação de um novo requisito de eficácia do contrato, baseada, como se refere Gorla, numa "limitação ao referido princípio do consenso, isto é, à sancionabilidade do contrato, um requisito que se distinguiria daquele da licitude do próprio contrato." Este requisito, segundo o autor, "consistiria na função social ou econômico-social que um dado contrato (lícito) deveria ter para merecer sanção jurídica; de outra forma, o contrato, ainda que lícito, seria "indiferente" para o direito. Segundo tal teoria, esta função econômico-social do contrato seria a causa no sentido próprio do contrato, isto é o "quid" que, ao lado da promessa ou do valor da palavra dada, justifica a sanção jurídica: não uma causa ou justificação consistente na exigência de oferecer justiça entre particulares, mas uma justificação que concerne ao interesse público ao reconhecimento de um dado contrato, pela função econômico-social que possui. ${ }^{, 28}$

Tais exacerbações dos conceitos nada têm de jurídicas ou de consentâneas com o ordenamento, e são rechaçadas, pela melhor doutrina, que concebe a função social do contrato não como critério revolucionário das estruturas, mas, coerente com a própria imagem do contrato, como resultado da liberdade individual.

Por outro lado, a própria idéia da função social do contrato, analisada com a devida ponderação, legitima um razoável grau de dirigismo contratual, incidente, em especial, àqueles modelos vinculados a estruturas padronizadas, que limitam a formulação bilateral das regras, próprias aos contratos de adesão, por exemplo. Assim, a razão está com Bessone, quando constata que, "se a lei não exige que o contrato seja preparado por uma livre discussão de suas cláusulas e contenta

27. Gino Gorla, Il Contrato, v. 1, 1ª ed., Milão, Giuffrè, 1954, p. 200.

28. Ob. cit., pp. 200 e 203. 
com o consentimento livre na sua conclusão, a regulamentação não exclui o contrato, nem altera o seu conceito. Entendemos que, se o contrato é o acordo de vontades que cria, modifica ou extingue relações jurídicas, de natureza patrimonial, sempre que a sua conclusão depender do acordo de vontades, para um dos fins indicados, haverá contrato, ainda que suas condições sejam estabelecidas por regulamento ou hajam sido preparadas unilateralmente por uma das partes, como sucede nos contratos de adesão. "29

IV - O contrato e o "contato social"

Verifica-se, afinal, que o consensualismo, a convergência de duas ou mais vontades - que se apresenta, em maior ou menor escala - como requisito para a formação dos contratos, aparece evidentemente mitigado, em algumas formas contratuais, deixando mesmo de existir em outras hipóteses, onde, se verifica a bilateralidade das obrigações, sem que se verifique, propriamente, a existência de um verdadeiro contrato.

Dentre tais expressões do contato social ou de verdadeiras relações contratuais de fato, Roppo faz menção às seguintes formas: ${ }^{30}$

a) Os chamados “Contratos automáticos" pelos quais é realizada uma oferta ao público, constituída pela presença de máquinas distribuidoras de pequenos bens de consumo, como aquelas de refrigerantes ou de balas, através dos quais o produto é adquirido mediante o depósito de moedas em coletores. Parece, nestes casos, evidente exagero impor a ficção de existência de um consenso eventualmente existente entre o dono da máquina e, por exemplo, um menor, que pudesse fazer abranger tal fenômeno dentre aqueles da convergência de vontades.

b) A "Contratação estandardizada" como sendo aquela realizada através do emprego de determinadas condições gerais, módulos e formulários, predispostos antecipadamente, por uma parte, para uma massa homogênea e indiferenciada de contrapartes (contratos de massa), traduzindo-se, tanto nas figuras do contrato-tipo, quanto nas imagens próprias ao contrato de adesão. Nestas, existe contrato, mas tal "declaração contratual se traduz num comportamento socialmente

29. Ob. cit., p. 49.

30. Cf. ob. cit., pp. 301 e ss. 
tipificado." Representam exemplos desta forma de contratação os títulos de crédito, as negociações em Bolsa, os contratos de seguro, etc.

Deste modo, o que se verifica é a inexistência de um formal consensualismo, da convergência de duas declarações de vontade verdadeiras e equivalentes. Contudo, e ainda seguindo o magistério de Roppo, em todas estas hipóteses, a relação contratual nasce e produz seus efeitos, não já sobre a base de declarações de vontade válidas (as quais, em linha de princípio, seriam necessárias para que existisse um contrato), mas sim com base no "contato social" que se estabelece entre as partes dessa mesma declaração, contato social este que poderia ser caracterizado como o "complexo de circunstâncias e de comportamentos valorados de modo socialmente típico através dos quais se realizam, de fato, operações econômicas e transferências de riqueza entre os sujeitos. "31

Todas estas circunstâncias, na verdade, delimitam situações emergentes na vida contemporânea, em relação às quais, em benefício da praticidade, celeridade e confiança nas relações, prescindiu-se de uma reafirmação mais efetiva da existência de declarações de vontade perfeitas e acabadas, que pudessem levar à sua classificação como verdadeiros contratos, mas que, exatamente pelo sinalagma que apresentam, merecem ter, quanto aos seus efeitos, a mesma interpretação.

V A intervenção estatal e as restrições da autonomia individual

Manifesta-se uma nova perspectiva da intervenção do Poder Público, neste sistema, como necessidade imprescindível para uma ampla gama de situações, quando, pela experiência ou visibilidade do desequilíbrio existente entre as partes contratantes, fica demonstrada, desde logo, que as cláusulas contratuais serão impostas de uma maneira eminentemente unilateral, representando, desde o primeiro momento, a sujeição de uma das partes à outra, no regime das trocas negociais.

Reconhecendo tal possibilidade, o Estado legitimamente interfere, através da imposição de cláusulas obrigatórias ou da fiscalização permanente, no sentido de equilibrar tal situação e, na verdade, garantir às partes melhores condições para o exercício de sua autonomia da vontade.

31. Enzo Roppo, ob. cit., p. 303. 
Tal situação ocorre em várias relações contratuais, nas quais se verifica a interferência do legislador na imposição de limites ao poder de uma das partes. Vários exemplos ocorrem em nosso ordenamento, como daquelas cláusulas obrigatórias que instituem prazos mínimos na locação residencial urbana; as que determinam percentuais mínimos de rendas que devem ser atribuídos ao parceiro outorgado ou arrendatário, nos contratos agrários; as que se referem às garantias de indenização, de férias, horas extras e licenças remuneradas, previstas nos contratos de trabalho; bem como as que regulam os direitos dos consumidores frente aos fornecedores de bens ou de serviços, da forma como, por exemplo, é regulado em nosso Código de Proteção e Defesa do Consumidor.

Em todas estas circunstâncias, mais do que limitar a autonomia da vontade das partes, a função do Estado é, propriamente, garantir condições semelhantes a ambas as partes que contratam para a expressão de sua liberdade contratual, e não apenas a uma delas que, em função de condições de favorecimento estrutural, possam, sem tal limite, fazer impor sua vontade à outra.

VI Conclusão - Os novos papéis do contrato

O que se conclui, portanto, é que, ao lado do modelo clássico do contrato, baseado na expressão da autonomia da vontade das partes contratantes e no equilíbrio existente entre estas mesmas partes, o que se verifica é a existência de novas formas contratuais e de novas relações derivadas da convivência social (que, ainda que não se constituam propriamente em contratos, se aproximam desta classificação, e devem ser como aqueles compreendidos, no tocante à produção de efeitos e na proteção das partes que destas relações participam).

Continua a existir, pois, o contrato tradicional, mas, por imposições do mercado e da necessidade de instrumentos ágeis que possibilitem a circulação da riqueza, legitimam-se, por exemplo, as figuras dos contratos-tipo e dos contratos de adesão, as quais, em verdade, tornam possível a própria contratação em massa, nas dimensões hoje existentes, o que seria mesmo inviável, tendo à vista o apego inafastável às formas tradicionais.

Por outro lado, considerando-se a existência das trocas existentes em sociedade e a ocorrência de transferências de bens e serviços, que se fazem comum e legitimamente entre os indivíduos, sendo instituídos efetivos vínculos sinalagmáticos mas sem que se verifique propriamente a formação de um contrato - baseadas que 
são tais trocas apenas e tão-somente num assim denominado "contato social". é de se admitir, também em nossa sociedade contemporânea, a necessidade do reconhecimento desta realidade pelo sistema, inclusive para garantir a segurança e confiança das partes que assim se relacionam, bem como para fazer valer, dentre outros, o princípio constante de nosso ordenamento que coíbe o enriquecimento sem causa.

Assim, de um lado, entende-se como conseqüência deste sistema, a necessidade de que seja, de fato, garantida a verdadeira e livre concorrência, compreendida esta como a existência de opções às partes que pretendem contratar. Este seria, no nosso modelo atual, o verdadeiro elemento caracterizador e garantidor da manutenção da autonomia da vontade, talvez preponderante, inclusive, em relação àquele da efetiva negociação de cada uma das cláusulas que compõem um contrato.

Além disso, considerando a fluidez e a contínua alteração deste sistema que envolve as trocas negociais, é de se entender a necessidade de complementação do ordenamento com um conjunto de regras que imponham às partes que contratam - ou simplesmente "contatam" - um modo de proceder que garanta às mesmas parâmetros de comportamento, os quais, segundo pretende a sociedade, devam ser genericamente respeitados.

Este é o princípio da boa-fé, que é reconhecido pelo ordenamento tanto através da criação de cláusulas gerais que definam o comportamento esperado das partes, ou que privilegiem a confiança nas relações, ou que imponham a assunção de riscos por alguma das partes que, por sua condição privilegiada, possa melhor carregar determinados ônus, em benefício daquela parte mais débil. $\mathrm{O}$ sistema, em verdade, deve estatuir regras com vistas à "exigência de tutelar a confiança, dando prevalência, pois, aos elementos exteriores, ao significado objetivo e típico do comportamento." 32

O contrato, em suma, surge ainda como verdadeiro e próprio instrumento da liberdade de iniciativa econômica, e neste sentido está mais vivo e forte do que nunca.

Ocorre que, em virtude de sua própria evolução, impôs-se o desenvolvimento, além daquele seu modelo clássico e, por assim dizer, "subjetivo" baseado na declaração que exprima a autonomia da vontade das partes que contratam, um outro modelo, fruto das imposições contemporâneas que clamam pela

32. Maria Costanza, ob. cit., p. 10. 
objetivação e homogeneização das formas e tipos. Este é, segundo afirma Roppo, “o 'modelo objetivo' de contrato - tal como um instrumento funcional necessário a uma economia capitalista, altamente desenvolvida, caracterizada por produções $e$ consumos de massa e, portanto, por um elevado volume das trocas. "33

Neste sentido, aproxima-se o instituto daquela definição de contrato do Direito Anglo-Americano, simplesmente como o "ato gerador de obrigações. "34

Portanto, o que cumpre reafirmar é a necessidade de que se tenha claramente, como idéia fundamental ligada à noção de contrato, a imagem de sua função realmente precípua, como instrumento da liberdade de iniciativa econômica, da liberdade de agir segundo os ditames do mercado, fazendo circular a riqueza e assim expressando esta forma de expressão da liberdade dos indivíduos.

São Paulo, janeiro de 1996.

\section{BIBLIOGRAFIA}

AGUILA-REAL, Jesus Alfaro. Las Condiciones Generales de La Contratacion. $1^{\text {a }}$ ed. Madri : Civitas, 1991.

BESSONE, Darcy. Do Contrato - Teoria Geral. $3^{\mathrm{a}}$ ed. Rio de Janeiro : Forense, 1987.

CORDEIRO, Antonio Manuel da Rocha e Menezes. Da Boa-Fé no Direito Civil. $1^{\mathrm{a}}$ ed. Coimbra: Almedina, 1984. v. 2.

COSTANZA, Maria. Profili Dell'Interpretazione Del Contrato Secondo Buona Fede. $1^{\text {a }}$ ed. Milão : Giuffrè, 1989.

DAVID, René. Les Contrats en Droit Anglais. $1^{\mathrm{a}}$ ed. Paris : Librairie Génerale de Droit et de Jurisprudence, 1973.

FERRI, Luigi. L'Autonomia Privata. $1^{\text {a }}$ ed. Milão : Dott. A. Giuffrè, 1959.

GILMORE, Grant. La Morte Del Contrato, tradução de Andrea Fusaro. $1^{\mathrm{a}}$ ed. Milão : Giuffrè, 1988.

GOMES, Orlando. Contratos. $12^{\mathrm{a}}$ ed. Rio de Janeiro : Forense, 1990.

GORLA, Gino. Il Contrato. $1^{a}$ ed. Milão : Giuffrè, 1954. v. 1.

33. Ob. cit., p. 310

34. René David, Les Contrats en Droit Anglais; $1^{2}$ ed., Paris, Librairie Génerale de Droit et de Jurisprudence, 1973, p. 64. 
PEREIRA, Caio Mário da Silva. Instituições de Direito Civil. $9^{\mathrm{a}}$ ed. Rio de Janeiro : Forense, 1992. v. 3.

RANOUIL, Véronique. L'Autonomie De La Volontè. $1^{\text {a }}$ ed. Paris : Presses Universitaires de France, 1980.

ROPPO, Enzo. O Contrato. $1^{\text {a }}$ ed. Coimbra : Almedina, 1988. 